\title{
The Writing of History and Return of Language: Art History as An Explanation Object-On Hubert Damsich's “A Theory of /Cloud/"'
}

\author{
Chai Dongdong \\ Department of Cultural Creativity, Hangzhou Normal University, Hangzhou, China
}

Email address:

chaidongdong2006@126.com

\section{To cite this article:}

Chai Dongdong. The Writing of History and Return of Language: Art History as An Explanation Object-On Hubert Damsich's “A Theory of /Cloud/". International Journal of Literature and Arts. Special Issue: Humanity and Science: China's Intercultural Communication with the Outside World in the New Era. Vol. 8, No. 3, 2020, pp. 162-168. doi: 10.11648/j.ijla.20200803.19

Received: February 27, 2020; Accepted: March 16, 2020; Published: April 23, 2020

\begin{abstract}
Giving a methodological and ontological explanation to the art history is the core thought of "a theory of /cloud/" of Hubert Damisch. It shows that there is no uniform explanation for art history. And the explanation of art history can only be placed in the framework of history. Language is the main reason for this, because it is historical, and through it the art history can be narrated and explained. As an explanatory activity, art history needs to plan a historical horizon which is different from the present, and integrate with the current horizon to explain historical events. Therefore, all art history is bound to be a historical explanation. This is the logic of why art history needs to be constantly renovated. On the other hand, because art history is inseparable from language, it must rely on linguistic methods in the specific analysis process. Taking this as his starting point, Damisch takes semiotics as the dominant method of explaining the art history. In his eyes, semiotics, as a method of combining meaning reading and characterization analysis, can effectively reconcile the contradiction between formal analysis and iconology. Not only that, the symbol as a kind of representation of representation can also make the painting back to the field of representation. Because representation is the basic purpose of painting. As a symbol, cloud precisely emphasizes that painting should pay attention to representation. And the sensibility and materiality of cloud in painting indicates that the painterly should become the mainstream of the representation. This kind of painterly is exactly what "A Theory of /Cloud/" aims to reveal. According to this, the painterly of painting should become the main focus of the writing of art history.
\end{abstract}

Keywords: Theoretical Object, Art History, A Theory of /Cloud/, Art Semiotics

\section{Introduction}

How to construct art history is the first problem that art historians have to face when art history became a discipline in Alois Riegl's time. However, when art history began to enrich itself by drawing on the achievements of aesthetics, of literature and of cultural theories since the middle of the 20th century, its relationship with art theory began to become more tense and subtle on the one hand, and the traditional interpretation modes of formal analysis and iconography began to be challenged on the other hand. Although new art history has brought new methods, the constant changes in art practice still prompt theorists to seek new modes of explanation. For the French art historian Hubert Damisch, the reason why art history can be constantly renovated is that people constantly put forward new questions. Then how to reconstruct art history under this new background? And what are the question patterns and attributes of this reconstruction? This paper takes Damish's A Theory of /Cloud/: Toward a History of Painting as an example, and tries to answer these questions through a case study.

\section{The Historicity of Art History: "Cloud" as a Theoretical Object}

Damisch's focus on the cloud came from an examination of Correggio's paintings of the domes of Palma's monasteries ("The Ascension of Christ", "The Coming of the Virgin"). The 
peculiarity of the paintings of domes lies in the treatment of architectural space. He finds that before and for a long time after Correggio, painters often treat the ceiling space in a hallucinatory way, emphasizing and highlighting the characteristics of the building itself and the hinged layout, that is, arranging the layout according to the standards of easel painting. But Correggio' approach is to negate the structure of the building itself, even the closure of the building itself. "After carefully selecting a location for the roof, a set is drawn that is conceived to feel as if 'holes are punched' in the wall above and to create an imaginary open space above the lifelike sky" (P. 2) [1]. The dominant style of painting since the Renaissance is the precise limit in any form of painting and Correggio's significance lies in that "In this kind of art, the three-dimensional perspective and closed orthogonal intersection of the construction of space criteria which was built in the 15th century Italian Renaissance painters gradually disappeared"(P. 4) [1]. And "The color transitions, shading, and presentation of Spaces, supports, and seating throughout the mural are accomplished through the clouds in the painting" (P. 3) [1]. In Wolfflin's view, the carnival of space and light presented itself uncontrollably in Correggio, and the effect of giving unlimited power to decoration only appeared in the late baroque period. In Riegl's eyes, Correggio's work occupies a decisive position in the connection between the objective and the subjective poles, and in the distinction between tactile and visual representations. For Damisch, the reason why these theorists believe that the convent dome is the initiator of baroque art lies not only in stylistic analysis, but also in "taste". In the 18th century, taste was the force on the optic nerve of an object intended to make the eye feel pleasure, which developed into the "style" theory.

Of course, in the history of western aesthetics, especially in Kant's case, the judgment of taste is also ultimately associated with pleasure. Taste corresponds to sensation, which emphasize to space, light and color. Correggio clearly occupies a "center of theoretical opposition that continues till today", which is the discussion of two different visual narrative mechanisms in art history triggered by the style change from Renaissance to baroque art depicted by Wolfflin, that is, the direct result of the beginning of the confrontation between linearity and painterly. In Correggio, the subject arranges the picture explicitly, comprehensively and consciously for the first time, which starts the transformation of painting from the classical flat to the modern space construction. This subject is in the sense of Kant, who accepted space as a transcendental form of sensation at the beginning (P. 10) [1]. In Damisch's view, the cloud is by no means a fantasy of Correggio, but acts as a free medium, participating in the whole process, having both descriptive and syntactic characteristics, being completely semiotic, and becoming a constructive material. In addition, the cloud also appeared frequently in paintings of the middle ages and of the Renaissance periods. The ubiquitous nuisances of cloud provides more convenience for the analysis from the perspective of semiotics, and also the possibility to explore another narrative.
To extend the theoretical analysis fields triggered by cloud, Damisch introduces the concept of "Theoretical Object". "A theoretical object is something that asks to work according to standards, and these standards are not historical. It is not sufficient to write a history of such objects. Nor is it sufficient to write a history of a problem in order to solve it. A theoretical object is something that oblige one to do theory" (P. 8) [2]. Not only that, it's the object that gives us the meaning of doing it in the process. "So, if you agree to accept it on theoretical terms, it will produce effects around itself" [2] 8. Finally, it is a theoretical object because "it forces us to ask ourselves what a theory is. It is posed in theoretical terms; it produces theory; and it necessitates a reflection on theory" (P. 8) [2]. Theoretical objects are diverse, some are subordinate to an almost ideal or conceptual order (whatever the patterns that history may endow them with), while others possess a property that is essentially physical and technological. In this sense, art constructs a theoretical object, because history has never determined its anthropological and speculative connotations. If we want to grasp the thought, we should construct the object of the theory. On the contrary, if we want to think about the theory itself, it is impossible to leave the object. The establishment of the theoretical object provides a basis point for Damisch's analysis of art problems, and the cloud becomes a unique theoretical object. As the blind spot that linear perspective cannot express, the cloud proves that the perspective establishes a closed space, an exclusive structure. But it also has a formal meaning, because it contains a definite and painterly concept of the painting space.. Cloud symbolizes the nature of painting. "The cloud introduces something that has no place in painting, but at the same time is painting itself. So painting is itself defined within this type of paradoxical" (P. 9) [2]. In other words, where the cloud is found is where it escapes, and when the painting disappears into the graphic system, it is the cloud that makes it discover itself. As the basis point of the whole work, cloud can penetrate into the inner operation of the system, demonstrate its limitations, and make the painting discover itself.

"A theory of /cloud/" thus becomes a method to explain art history, and historicity is its main characteristic. In Damisch's view, since the word theory implies continuity, it implies history, so "a theory of /cloud/" should be about all clouds in history, at least relative to the history of painting. Damisch's theoretical object is like a model of thinking, and its operation logic is very similar to that of a chess game. Just as Duchamp's tireless exploration of the relationship between chess, painting, aesthetics, and language. Chess and painting simultaneously serve as an intellectual activity and provide images for thinking. The difference between chess and history is that in a chess game given complete information, each position gives the player all the information he needs to decide what to do next, whereas history does the opposite. The displacement of a piece depends on timing, while the displacement of each step depends on the result of the displacement of the previous step. History becomes a point of connection. But the uniqueness of chess is that it can simultaneously play synchronic and diachronic, both concrete and abstract, which can effectively 
avoid the reduction of linear historical view. The word history itself does not have the same resonance, and the concept does not work the same way when applied to art, science, and other topics. But when we assert an object and begin to tell a story about it, we begin to make a history. Therefore, in terms of its explanation method, "a theory of /cloud/" firstly emphasizes the historicity of explanation: that is, the understanding of objects in history and the historical narration in objects. In fact historicity is also a general rule in Damisch's understanding of works of art, just as he repeatedly asks why works of art in history have sustained appeal, which makes him pay particular attention to the importance of pre-understanding and temporal distance in explanation. In his view, as a person who is standing at a certain historical point to understand the works of art in the past, one must look forward and backward at the same time (as in chess) before one can determine one's own vision (P. 10) [2]. Today's perspective provides us with a new inspiration point, and works can regain their value.

Damisch does not think that we can hold a kind of Baxandall's "Eyes of the Times" to carry out explanation activities, but he emphasizes a fusion of horizons in hermeneutics horizon. According to the philosophical hermeneutics, the understanding of tradition undoubtedly needs a historical horizon. Since we are historical beings, our cognition also begins with what is historically given, which is the basis of all subjective attitudes and opinions. Since horizon is essentially a concept of situation, and our hermeneutics situation is always influenced by the effective-historical, the formation of our horizon is related to pre-understanding. In short, the activity of explanation is to plan a historical horizon which is different from the present. When Damisch thinks about art with a structuralist model, it is obvious that he shares a hermeneutics logic. What he meant by the theoretical object was to lay a foundation for the theory, to make it more concrete and practical, so as not to fall into the situation of too abstract and generalized. As far as the academic definition of the word theory is concerned, it represents interdisciplinary, analytical and speculative, criticism of common sense, criticism of the concept identified as nature, thinking about thinking (reflexivity), and a tool for us to ask questions in discourse practice (P. 16) [3]. But in fact, the specific, contextualized and localized knowledge is always in flux, and the constitutive laws of theories cannot remain eternal, but only have relative stability. It is in this sense that Damisch especially emphasizes the priority of the object to the theory, and the priority of the historical horizon makes the theory constructed around the object concrete, open and polyphyletic.

It can be seen that the theoretical object is not only the setting of the problem structure, but also a kind of pre-planing activity. Because in the process of understanding, each revision of pre-planning activity can make a new meaning of planing, pre-grasp is constantly replaced by a more appropriate grasp, so the theoretical demonstration around the object constantly gives rise to a new understanding, and further promotes the development of the theory. From this point of view, Damisch's theoretical object at least emphasizes the importance of historical and problem consciousness to understanding and explaining activities. So "a theory of /cloud/" is a broader explanation of how to do or explain the art history. It tells us that in order to explain art history, we must first have question consciousness, which is formed on the basis of specific pre-possess, pre-cognition and pre-grasp. Therefore, all writing of art history must be a historical explanation and a process of fusion of horizons. This is the reason why art history needs to be constantly renovated, and also the reason why art works have a continuous attraction. In fact, French art history writing didn't experience an effective separation process between "art history" and "art criticism" compared with the art history writing in English-speaking world. The reason lies in that regarding the painting as a symbol system and then exploring its relationship to history is a basic standpoint to new art history of France. For Damisch, structure (symbols) and historical investigation are inseparable from painting. Because, "painting is a unique object in the study of history, and it must be treated in this form: it implies the paradox that the researcher must absorb a cautious structuralist view, which makes the phenomenal dimension of history more vivid" (P. 444) [4]. In a word, Damisch redefines the role of history in the history of art by repeatedly demonstrating that only a theoretical perspective enables us to see a work of art as a historical entity.

\section{Narrative and Mediation: "A Theory of /Cloud/" as a Semiotic Explanation Method}

Damisch's theoretical object shares the same logic with Adorno's reference to Benjamin's concept of "constellation" from the standpoint of opposing the philosophy of identity. This kind of treatment not only pays attention to the object priority of phenomena, but also can express the truth, which conforms to the logic of postmodern philosophy. As a result, Damisch's theoretical starting point is not limited to traditional art history writing, but has higher historical and philosophical goals. In addition, he intends to deal with hegelianism in the study of art history, which leds him to take a third path in methodology, apart from formal analysis and iconography.

In particular, Damisch doesn't attempt to summarize a general style shift like the formal analysis but treat the cloud as a kind of unique case in art history, to explore the function of cloud in different historical periods and the constraints of its unique historical and knowledge mechanism, such as the interactive relationship between painting and drama, painting and science. In terms of the specific analysis of paintings, he directly uses the tools of semiotics to analyze the intertextual relations among the painting components, and paid more attention to the investigation of the meaning of pictures. But in the historical investigation of cloud, it is more inclined to the motif studies. In this sense, Damisch is close to iconography at the most basic level of analysis. But his emphasis on the problems of taste caused by the cloud resulted in the 
development of a style that emphasized sensation and materiality. So in terms of the overall goal it is formal analysis, with a similar logic to Wolfflin's description from line to graph.

So how to define "a theory of /cloud/"? In fact, this is closely related to its direct analysis tool In Damisch's view, painting is first and foremost a system of expression, which determines the noumenon of painting itself and reflects the possibility of a system of its own. Then the tool to demonstrate the evolution of the system, in his view, is the symbol. Not only that, semiotics begins to assume the function of iconography in the new theoretical context. In his view, iconography seems to explain the introduction of problematic symbols into the study of art because of its interpretation of the theme, story, allegorical world of images and the world that constitutes the "symbolic" value in the moment of realizing that meaning (P. 105) [5]. At the same time, it also proves in the opposite direction that images need to be further interpreted in addition to the direct perception and thinking. In order to explain that images can be broken down into various units, semiotics and narrative structure analysis are more possible. This is the most direct connection between iconography and semiotics. Although iconography basically attempts to state what images represent, semiotics attempts to disassemble the mechanics of representation and show the representation process. But as far as iconography itself is concerned, it has implied a reference to the existing knowledge system at its primary level and it is earlier than the interpretation. This kind of knowledge is called enlightenment which is engraved in the deepest level of the cultural individual and finally serves the need of analysis together with the order of text. From this point of view, interpretation predates the emergence of semiotics, which has existed since the establishment of iconography itself. However, interpretation does not imagine images as texts, but introduces the authority of texts into image analysis and obtains arrangements from texts through symbolism (P. 106) [5]. Therefore, any iconological interpretation of the image must rely on the chain of words, that is, the text or narration ultimately announces the meaning of the image. The more fundamental fact is that the idealized image concepts implicit in the iconography approach are difficult to disassociate with the structure of representation (P. 106) [5].

So iconography is deeply rooted in the metaphysical soil of symbols, both as an interpretive tradition and as a struggle between images and symbols (a tradition that began with Plato). Because iconography is committed to expanding itself from the privileged position of the representation system, but the representation system creates a rupture between the natural and symbolic aspects of the symbols. When Ripa first used iconography to illustrate the logic of images and the procedures related to image narration, his purpose was to show what was different from what people saw, and to explore the traditional meaning of images, rather than the natural meaning, which was exactly a response to the rupture caused by symbols entering the representation system in its initial formation. In addition, the rise of iconography is the result of integrating formal analysis, which further determines the explanatory power of semiotic analysis in the study of art history. In fact, for Panofsky, the master of iconography, semiotics was also an underlying premise of his theory. In Danto's view, Panofsky transformed from a neo-kantianism into a Saussure scholar of artistic symbols. Because, "for Panofsky, there was no progress in the history of art, but only the development of different symbolic forms in different periods, until some internal upheavals come, because a new change is made, and a new set of symbolic form is made" (P. 73) [6]. Of course, Panofsky's exposition of the Prspective as Symbolic Form was indeed influenced by Cassirer's philosophy of symbolic form. From Panofsky's association with semiotics, it can be concluded that he and Damisch actually share a semiotics logic.

Semiotics as a method to explain art history, which integrates formal analysis and iconography, as Norman Bryson says, it is involved in a series of questions that are very different from early Riegl, Panosfky, and Shapiro. "Contemporary scholars of semiotics and art history have entered into a new field of debate: the diversity of meanings; author, context and acceptance; descriptive research on images; gender differences in words of visual symbols and their demend for the authenticity of explanation" (P. 93) [7]. Semiotics begins to challenge established notions of knowledge. Not only that, "semiotics, by its nature, can be applied to objects of any symbolic system because of its trans-disciplinary state" (P. 96) [7]. In terms of historical idea, this integrated semiotics is different from the traditional iconography and formal analysis. As "a theory of /cloud/" does the work of concretization and non-identity, it emphasizes the concretization and conceptualization of history, whose logic is from the general to the particular. In the context of the new social and theoretical, image study and cannot take into account the latest linguistic form analysis, psychological analysis, the effects of Marxism on the knowledge model, not to mention the latest "pictorial turn" (the "pictorial turn" is W. J. T. Michel's extended thinking along the two paths of Panofsky and Gombrich, a kind of post-semiotic study). Under this premise, semiotics, which has a wider explanatory power, has come to the foreground of art history study.

Of course, "a theory of /cloud/" is a case study after all, but through the integration of semiotics to formal analysis and iconography, it just becomes an effective mediation means. As an explanation method, it points out that only by reconstructing a system of art history can an effective coordinate system be established for the development of art itself. Moreover, heterogeneity and openness should become the mainstream of the explanation of art history in the new period, because even if they follow the same discourse background, if they are replaced at the level of symbols, they will destroy the identity due to the variability and non-universality of symbolic meanings. It can be seen that the new syntax of painting history created by "a theory of /cloud/" has a strong symbolic value, which indicates the change of explanation paradigm. 


\section{Painting as Noumenon: The Hermeneutics Significance of "A Theory of /Cloud/"}

Regardless of the emphasis on history, or the reconciliation of the traditional paradigm of art history, "a theory of/cloud/" is in terms of explanation methods. However, if we connect the emphasis of cloud on the nature of painting itself, we can see that "a theory of/cloud/" also has an ontology dimension. As in Correggio's painting, "it is only to satisfy one's own feelings, entirely according to one's own feelings because of painting is pleasing by sight" (P. 11) [1]. In contrast to the emphasis on feeling in baroque art, Correggio is indeed extremely pre-historical, which indicates that there are always two opposite poles in Renaissance art: to continue regard art as merely an adjunct to philosophy, or to emphasize the autonomy that art should have. However, this does not mean that the linear perspective controlled by naturalism does not reflect the autonomy of art, but in Damisch's view, it is missing the canvas, color, brush strokes and other things that painting should have, but these are where painting can tell the truth. This is why he advocates Cezanne's later works strongly. In contrast to the impressionist Monet, who used only color to melt shapes, Cezanne was no longer concerned with recording impressions, but with relaying feelings. "In the gap, in the blank of the portrait, the canvas begins to reveal its own materiality" (P. 255) [1]. Damisch attributes this change to the transition from portrait to painting, which focuses on strokes rather than lines, and above all on visual perception. "Making each level through the intensity of the light magnitude and get the sensation of the arrangement, as well as color sensation" (P. 256) [1].

Damisch is clearly following the same path here as Greenberg. Because in Greenberg's case, medium (that is, planeness) is essential to painting, which refers to painting as painting. And what modernism requires is the return of painting to this. But Damisch's materiality pays more attention to the role of the sense. And what he called the painterly nature of painting is exactly the visual impulse brought to the subject by the image constituted by colors, strokes, etc., that is, the thing that can generate taste (meaning/organ). It has to be said that Damisch also shares Greenberg's conclusion. He also regarded the construction of art's own system as the main task of his art history study. His "theoretical object" also shows at another level that art could independently undertake a rational plan and art could generate thoughts. Importantly, Greenberg clearly pointed out that painting's self-discipline was the most fundamental way of existence of painting, which obviously pointed to a kind of ontology. However, when Damisch push this idea into the field of sensation and organ (body), he is closely related to the phenomenology and hermeneutic tradition.

Under the direct influence of Merleau-Ponty, Damisch goes to the "eye seeing" paradigm to emphasize the relationship between painting and body, which is different from the "mind seeing" paradigm emphasized by the phenomenology of consciousness from Descartes and Hegel to Husserl. According to Merleau-Ponty, "mass, light, color, depth, they are all there facing me, they are there only because they awaken an echo in our bodies, only because our bodies welcome them" (P. 131) [8]. The identity of painting and body determines that there can be unhindered communication between the body and painting. For the painter, visual activity is to let the reflection of the material germinate in his body, instead of passively letting the material be described by the painter. Therefore, the painter's visual activity is the primary recreation, will cause the painting style changes. For Damisch, the physical nature of the cloud meant that it needed not only space and color to be represent, but also a metaphor for the body, because the cloud, as vapor in the meteorological sense, was inherently bound up with the body breathing the atmosphere. And his repeated emphasis on taste echoes Merleau-Ponty' advocacy of "eye seeing". But Damisch's emphasis on visual perception is tactile, and clouds at least provide the viewer with a psychological sense of touch. This sense of touch is different from Riegl's. His theoretical starting point is to avoid the extreme subjectivism and solipsism tendency in art caused by pure visuality. The reference is an analogy with sculpture, which stands on the sublimation of art from material to form (spirit) since Hegel, and the sense of touch is not high-end here. Damisch's starting point is the analogy with the art dominated by purely linear perspective. He wants to find the subjectivity of painting history through materiality, and to find what is "the logic of sensation" of Deleuze, that is, the image is the shape that can be sensed by being pulled to the level of sense, which directly acts on the body. In this way, on the dome of the Parma monastery, the cloud, as a machine with a clockwork, generates movement and guides the viewer to go into it. It is here that the cloud provides incomparable material for sensation.

Through phenomenology, "a theory of /cloud/" has an anti-metaphysics background. Just as Richard Rorty summarized modern western philosophy's view of the mind as a mirror reflecting reality as "presentationism", in the field of vision, the most important result of this theory is the discovery of linear perspective. The intersection of the vanishing point and the viewpoint is in a straight line, which also means that the construction of the painting space is completely dependent on the viewpoint of the subject, and the visual image thus established is completely subordinate to the mind. In Panofsky's point, the rediscovery of the problem of linear perspective reflects a major shift in the cognitive structure of the Renaissance, which is the inevitable result of the weakening of religious control and the resurgence of rationality. From this point of view, Damisch treats "cloud" as the entrance to prove the incompatibility of linear perspective not only advances the possibility of constructing a sensibility painting history, but also finds a certain source for its generation.

If the emphasis of "a theory of /cloud/" on the materiality of painting reflects the exploration of the noumenon of painting and makes the way of existence of painting return to the level dominated by the painterly of painting, then it makes painting as an ontological event possible with the help of the anti-metaphysics of the body. Referring to Heidegger, the thing is the most basic condition to open the individual things in the art 
works. In the path of truth manifestation, the thing and the art work are inseparable from each other. When the being of works is to establish a world, art has an ontological status. It is in this sense that Gadamer identifies painting as an ontological event in his philosophical hermeneutics. As an ontological event, painting is not grasped on the object that is understood as a certain aesthetic consciousness, but on the level of meaningful visible manifestation that being in it. In this case, the painting itself is what is meant. "The important thing is what it represents in which way does it represent itself" (P. 182) [9]. Since the representation is always related to the prototype, and the prototype achieves the representation in the representation, so the prototype undergoes an expansion through the representation and the uniqueness of painting lies in the streaming of the prototype. From the ontological relation between representation and painting, we can see Damisch's ontological position when he emphasized painting as a system of representation. For him, body and sensation are also defined in the representation.

Therefore, "a theory of /cloud/" implies a turning that from describing a noumenon to painting as a noumenon after emphasizing the self-discipline problem of painting. Its structuralist appearance is only a shallow level of narration and a direction for us to attach importance to the nature of the text. While its phenomenological background successfully outlines a problem of the manifestation of painting truth. What it tells us is that when we explain painting, we can only see the essential problem when we treat painting as a representation in the dimension of the material plane. What Damish wants to overturn here is the history of painting that describes painting and the things it imitates with a logic of identity, so that the writing of history of painting really moves towards the history of discovering painting itself, its irreplaceability and sacredness as the main task.

\section{Conclusion}

Just as Damisch makes it clear that his study of the cloud is to establish a new history of painting, "a theory of /cloud/"should first solve the problem of how to explain the history of painting or how to write the history of painting in the contemporary context. It establishes a historical and ontological principle of explanation, and explores the possibility of a new narrative syntax as a concrete case. As a history of painting syntax, it reconciles formal analysis and iconography, and emphasizes the importance of archaeological excavation within the visual system. As a theoretical deduction, its pre-understanding is subject to the radical theoretical changes in philosophy, literature and art since the 20th century, especially the 1960s, and shares a common clue with many theorists of the same period: the emphasis on painting as painting. Damisch's view of history obviously follows in Foucault, and aiming to define the relationship between visual cognition and the writing of art history in a vertical and fractured history. Art is not only a part of human spirit and history, but also has its own life and history. The development of art history is a kind of history of continuous self-reflection, just as art science is constantly self-defining in its entanglement with aesthetics and philosophy, that is, opposition and reference. The rise of new art history is still this hidden clue at work.

But what leds to the reexplanation of art history? In the final analysis, it is still a question of language. It is undeniable that the new art history is the result of a linguistic turn in the field of philosophy. As long as we review Damisch's study of art history, we will find that visual art has become a symbol system, which is full of literary nature and discourse. In the beginning of his book Picture Theory, Michel, a scholar of new art history who proposed "pictorial turn", points out that Damisch is one of the earliest scholars who made art history open to linguistics. The question is, can the language here be replaced by the language of art? Heidegger, a representative who criticizes metaphysics with language, holds that art is language, and it is the business of thinking and poetry to liberate language from grammar and make it enter into a more original essential structure. However, the essence of art lies in the fact that truth is put into works by itself, and "beauty" appears at the moment when truth is put in, so the language of art needs to rely on things or beauty to be appeared. Therefore, the language of art is different from the language of philosophy, but only has the necessary characteristics of the language of philosophy. The language of "linguistic turn" is a transcendental language. So, if there was a linguistic turn in art history studies then the art history studies must be shared with the logical premise of linguistic turn, meaning that it would no longer be the position of the theory of representation and would turn to discourse analysis. However, when representation begins to become the center of explanation, does the "linguistic turn" not logically collude with the pictorial turn? W. J. T. Michel is keenly aware of this problem, so he still draws the pictorial turn within the framework of linguistic turn. He believes that "pictorial turn" occurs just because there is a need to protect speech against vision.

Of course, "linguistic turn" does not discard images but to explore more meanings of images by introducing this paradox. In "a theory of /cloud/", for example, Damisch advocates the charm of painting for the viewer on the one hand and avoids disposing the image in a pragmatic sense on the other hand. He works to discover the inner workings of a text system. However, this semantic disposing mode does not discard the interaction between the subject and the text, and then developed a set of visual internal discourse system integrating the two. Thus, "a theory of /cloud/" not only points out the clue that art is moving towards self-examination under its relationship with history but also indicates that new art history still has to wander between "pictorial turn" and "linguistic turn" in terms of explanatory methods. However, this is not to reconstruct the language view of the pre-critical paradigm, but to look at the problem from the perspective of the rethinking on metaphysics. It is inevitable that a fusion of horizon from the perspective of hermeneutics will be achieved by examining the "linguistic turn" after the "pictorial turn". Just as Heidegger endowes language with a metaphysical foundation in his later period, this situation will lead contemporary art to re-maintain metaphysics and to realize the 
construction of a new introspective discourse. Of course, in the era when capital increasingly dominates art production, art still cannot escape the control of capital and ideology, but as long as we affirm the spirituality of art, the process of charming the art will continue.

\section{Acknowledgements}

This work is supported by the Youth Project of "Damisch and the Paradigm Shift of Art History Writing in the 20th Century" from Humanities and Social Science Fund of the Ministry of Education of China [Project No.: 18YJC760003], and the Innovation Project "The Study on Michael Baxandall's Image Explanation Thought" from Institute of Hermeneuties of Guangdong University of Foreign Studies [Project No. CSY-2019-17].

\section{References}

[1] Hubert Damisch. A Theory of /Cloud/: Toward a history of Painting. Trans. Dong Qiang. Nanjing: Jiangsu Fine Arts Press, 2014.
[2] Yve-Alain Bois, Denis Hollier, Rosalind Krauss and Hubert Damisch. "A conversation with Hubert Damisch", October, 85 (Summer 1998): 3-17.

[3] Jonathan Kahler. Introduction to Literary Theory. Trans. Li ping. Nanjing: Yilin press, 2008.

[4] Hubert Damisch. The Origin of Perspective. trans. John Goodman. Cambridge, Mass: The MIT Press, 1994.

[5] Hubert Damisch. "Semiotics and Iconography". Trans. Yu Huoxing. Journal of Hundred Schools in Arts, 2014 (4): 105-107.

[6] Chen huaien. Iconography: The Meaning and Interpretation of Visual Arts. Shi Jiazhuang: Hebei Fine Arts Press, 2011.

[7] Norman Bresson. "Semiotics and Art History". Trans. Yu Huoxing. The Art World. Ed. Wang Tingxin. Nanjing: Jiangsu Fine Arts Press, 2013.

[8] Merleau-Ponty. Eye and Mindt: Collection of Merleau-Ponty's Phenomenological Aesthetics, Trans. Liu yunhan. China Social Sciences Press, 1992.

[9] Gadamer. Truth and Method. Trans. Hong Handing. Shanghai: Shanghai Translation Press, 2004. 